\title{
Effect of cryogenic treatment on the fatigue crack propagation behavior of 7075 aluminum alloy
}

\author{
Di Xie ${ }^{1}$, Sujun $\mathrm{Wu}^{1}{ }^{1}$, Juan Guan ${ }^{1}$, Lin Yan ${ }^{1}$ and Jinyan Cui ${ }^{1}$ \\ ${ }^{1}$ School of Material Science and Engineering, Beihang University, Beijing 100191, China. \\ awusj@buaa.edu.cn
}

Keywords: cryogenic treatment, fatigue crack propagation, XRD

\begin{abstract}
This paper studied the effect of cryogenic treatment on the fatigue crack propagation property of 7075 aluminum alloy at a series of cryogenic temperatures using mechanics testing. Three cryogenic temperatures were chosen for cryogenic treatment: $-60^{\circ} \mathrm{C},-120^{\circ} \mathrm{C}$ and $-196^{\circ} \mathrm{C}$. The result showed that cryogenic treatment, especially at the cryogenic temperature of $-120^{\circ} \mathrm{C}$, can significantly improve the fatigue performance. The X-ray diffraction (XRD) result showed the cryogenic treatment caused the XRD diffraction peak intensity of (200) obvious enhanced. The tendency of XRD diffraction peak intensity of (200) was in good consistence with that of fatigue crack propagation behavior of 7075 aluminum alloy after cryogenic treatment. Therefore, the mechanism for the improvement in fatigue crack propagation property is proposed to be the preferred orientation of crystalline grains through cryogenic treatment.
\end{abstract}

\section{Introduction}

7000 series ultra-high strength aluminum alloys are widely used in aircraft and aerospace areas because of its excellent mechanical properties and corrosion resistance. At present, there are extensive studies on how to improve the mechanical properties and corrosion resistance of $\mathrm{Al}-\mathrm{Zn}-\mathrm{Mg}-\mathrm{Cu}$ alloys for its industrial applications by controlling the heat-treatment (solution heat treatment or artificial aging) process ${ }^{[1,2]}$.

Recent studies have indicated that cryogenic treatment is an essential supplementary treatment, following the conventional heat-treatment, which can significantly increase some mechanical properties of some alloys ${ }^{[3-7]}$. The mechanism of cryogenic treatment on ferrous material has already been well studied, which is the treatment promotes the transformation of retained austenite into martensite and lead to more homogenized carbide distribution ${ }^{[8]}$. However, only a few studies have reported the same effect on aluminum alloys. C.M. Li et al. ${ }^{[9]}$ proposed that the cryogenic treatment could induce phase transformation which varies the microstructures and affects the mechanical properties of the aluminum alloy. D. Chen et al. ${ }^{[10]}$ found that cryogenic treatment could change the diffraction peak intensity of some crystal planes in these alloys and proposed the volume shrinkage and crystal plane turn. Nevertheless, the effect of cryogenic temperature on the fatigue crack propagation behavior of aluminum alloys have not been well studied.

The purpose of this study is to evaluate the effect of cryogenic treatment on the fatigue crack propagation behavior of 7075 aluminum alloy at a series of cryogenic temperatures.

\section{Experimental techniques}

\section{1 material}

In this work, cryogenic treatment was applied to 7075 aluminum alloy. The chemical composition of 7075 aluminum alloy was illustrated in table 1. 
Table1 The chemical composition of 7075 aluminum alloy (wt.\%)

\begin{tabular}{ccccccccccr}
\hline $\mathrm{Si}$ & $\mathrm{Fe}$ & $\mathrm{Cu}$ & $\mathrm{Mn}$ & $\mathrm{Mg}$ & $\mathrm{Cr}$ & $\mathrm{Zn}$ & $\mathrm{Ti}$ & $\mathrm{Zr}$ & $\begin{array}{c}\text { Total } \\
\text { other }\end{array}$ & $\mathrm{Al}$ \\
\hline 0.12 & 0.15 & $2.0-2.6$ & 0.1 & $1.9-2.6$ & 0.04 & $5.7-6.7$ & 0.06 & $\begin{array}{c}0.08-0.1 \\
5\end{array}$ & 0.15 & bal \\
\hline
\end{tabular}

7075 aluminum alloy specimens were first subjected to conventional heat-treatment including, solution treatment at the temperature of $466^{\circ} \mathrm{C}$ for $60 \mathrm{~min}$, followed by water quenching and then two-stage aging at temperatures of $107^{\circ} \mathrm{C}$ for $6 \mathrm{~h}$ and $163^{\circ} \mathrm{C}$ for $18 \mathrm{~h}$. The obtained specimens were used as control and reference alloy to the cryogenic treated specimens. The heat treatment process of 7075 aluminum alloy was shown in Table 2. For the cryogenic treatment specimens, the cryogenic treatment was performed directly after water quenching and followed by the two-stage aging at the temperature of $-60^{\circ} \mathrm{C},-120^{\circ} \mathrm{C}$ and $-196^{\circ} \mathrm{C}$. The cryogenic treatment consisted of three steps, first slowly cooling water-quenched specimens to the fixed low temperature and holding at this temperature for $2 \mathrm{~h}$, then bringing the specimens back to room temperature.

Table 2 The heat treatment process of 7075 aluminum alloy

\begin{tabular}{cccc}
\hline Number & Solution treatment & Cryogenic treatment & Aging treatment \\
\hline A & $466^{\circ} \mathrm{C}$ for $1 \mathrm{~h}$ & ---- & $107^{\circ} \mathrm{C} \times 6 \mathrm{~h}+163^{\circ} \mathrm{C} \times 18 \mathrm{~h}$ \\
B & $466^{\circ} \mathrm{C}$ for $1 \mathrm{~h}$ & $-60^{\circ} \mathrm{C}$ for $2 \mathrm{~h}$ & $107^{\circ} \mathrm{C} \times 6 \mathrm{~h}+163^{\circ} \mathrm{C} \times 18 \mathrm{~h}$ \\
C & $466^{\circ} \mathrm{C}$ for $1 \mathrm{~h}$ & $-120^{\circ} \mathrm{C}$ for $2 \mathrm{~h}$ & $107^{\circ} \mathrm{C} \times 6 \mathrm{~h}+163^{\circ} \mathrm{C} \times 18 \mathrm{~h}$ \\
D & $466^{\circ} \mathrm{C}$ for $1 \mathrm{~h}$ & $-196^{\circ} \mathrm{C}$ for $2 \mathrm{~h}$ & $107^{\circ} \mathrm{C} \times 6 \mathrm{~h}+163^{\circ} \mathrm{C} \times 18 \mathrm{~h}$ \\
\hline
\end{tabular}

\subsection{Techniques}

In this study, all the specimens were processed according to the standard of GB6398. The schematic of sampling was shown in Fig. 1. The fatigue crack growth test was performed on compact tension samples in the orientation of L-T. The fatigue crack propagation testing was carried out on the Instron8801 test machine at room temperature. Fatigue crack growth tests were under a constant tension with the constant stress rate of $0.1(\mathrm{R}=\mathrm{rmin} / \mathrm{rmax})$ and constant frequency of $15 \mathrm{~Hz}$.

Scanning electron microscopy (SEM) and X-ray diffraction were also employed. The fatigue fracture surfaces were cleaned up with acetone solution for $30 \mathrm{~min}$ in ultrasonic cleaning machine and dried up with alcohol before facture analysis. The morphologies of fatigue fracture surfaces were observed on JM6010 scanning electron microscopy (SEM). X-ray diffraction (XRD) pattern was obtained by Rigaku D/max2200PC X-ray diffractometer with scanning speed of $4 \% \mathrm{~min}$, voltage of $40 \mathrm{KV}$ and Current of $200 \mathrm{~mA}$.

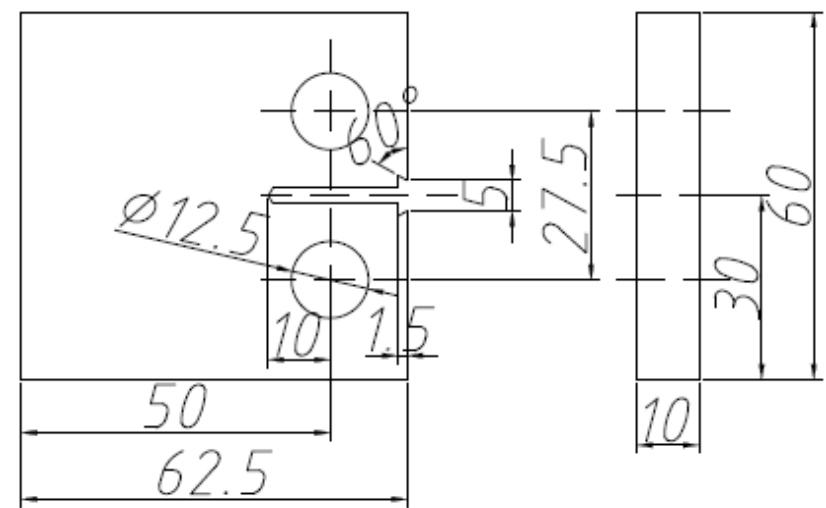

Fig. 1 Schematic of compact tension sampling

\section{Result and discussion}

\section{1 fatigue crack test}

Fatigue crack growth curves were shown in Fig. 2. From a whole perspective, the fatigue crack growth rate was increasing with the $\Delta \mathrm{K}$ increasing. The fatigue crack growth line of specimen $\mathrm{C}$ was 
in the lowest position, which suggested the specimen with cryogenic treatment of $-120^{\circ} \mathrm{C}$ exhibited the best fatigue performance. The fatigue crack growth line of specimen $\mathrm{B}$ was in the lower position which showed the specimen after cryogenic treatment of $-60^{\circ} \mathrm{C}$ exhibited relatively better fatigue performance. The crack growth rate of specimens $\mathrm{B}$ and $\mathrm{C}$ tended to slower than other treatment at the steady propagation stage. The crack growth rate of specimen D propagated faster than specimens $\mathrm{B}$ and $\mathrm{C}$ with the fatigue crack growth curve of specimen $\mathrm{D}$ almost overlapping with that of conventional treatment. From above discussions, it seemed that specimen after cryogenic treatment of $-120^{\circ} \mathrm{C}$ showed best resistance to fatigue crack propagation.

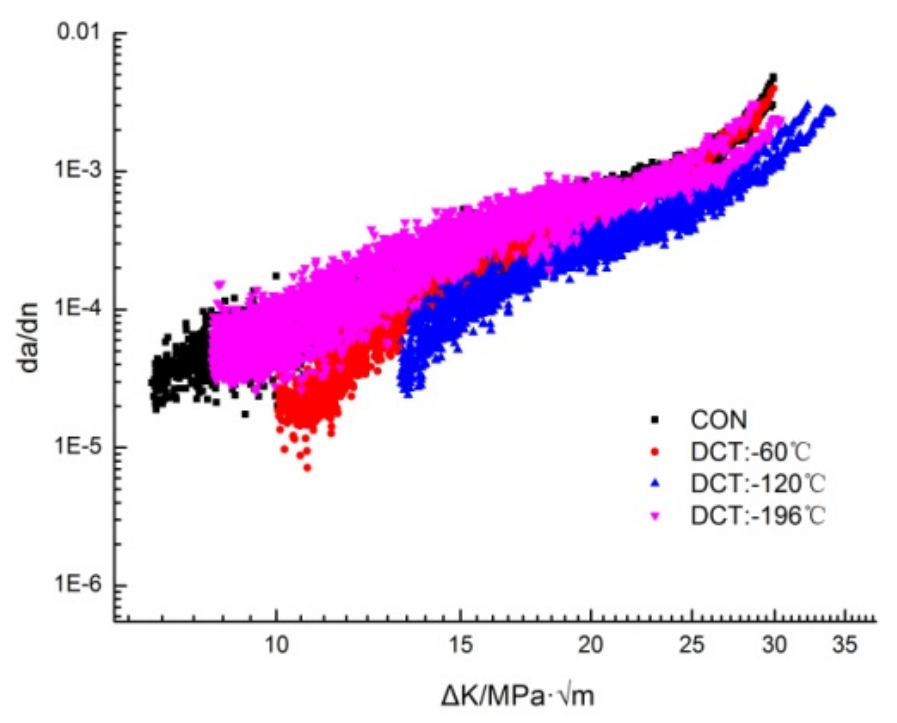

Fig. 2 Fatigue crack growth curves of 7075 aluminum alloy

\subsection{SEM observation}

To analyze the effect of cryogenic temperatures on the fatigue crack growth rate of 7075 aluminum alloy, fracture surface analysis was applied by electronic scanning electron microscopy to analyze the fracture characteristics. Figs. 3 showed the SEM fractographs of initial path of crack. Morphology of fatigue source zone was typical cleavage morphology, fracture surfaces were smooth.

The steady propagation and final fracture region got particular attentions because of more obvious difference at the two parts. Fig. 5 showed the final fracture regions, similar to characteristic of tensile fracture[11], were mainly consisted of transgranular dimples. It can be seen that specimen $\mathrm{C}$ contained more transgranular dimples. In the steady propagated area, typical fatigue striations and secondary cracks can be obviously observed (Fig.4). It can be seen that specimens B and C, especially specimen $\mathrm{C}$, exhibited more tortuous crack path and obvious fatigue steps. Based on energy consideration[11], the growth of tortuous crack path needed more energy, which leaded a relatively slower crack growth rate was achieved. Therefore, the specimen after cryogenic temperature of $-120^{\circ} \mathrm{C}$ showed the best resistance to fatigue crack propagation. 


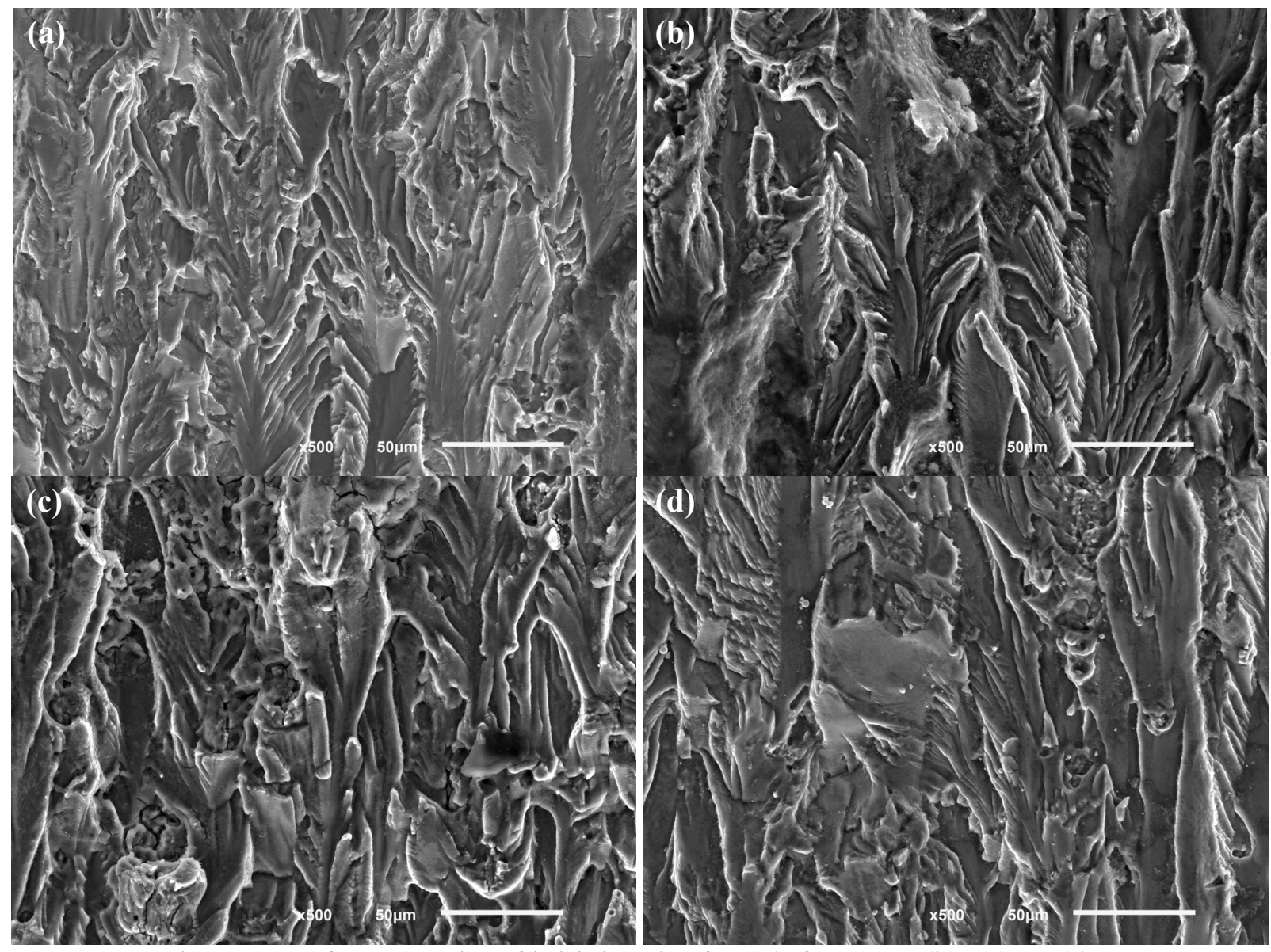

Fig. 3 SEM fractographs of initial path of crack for: (a)A (b)B (c)C (d)D

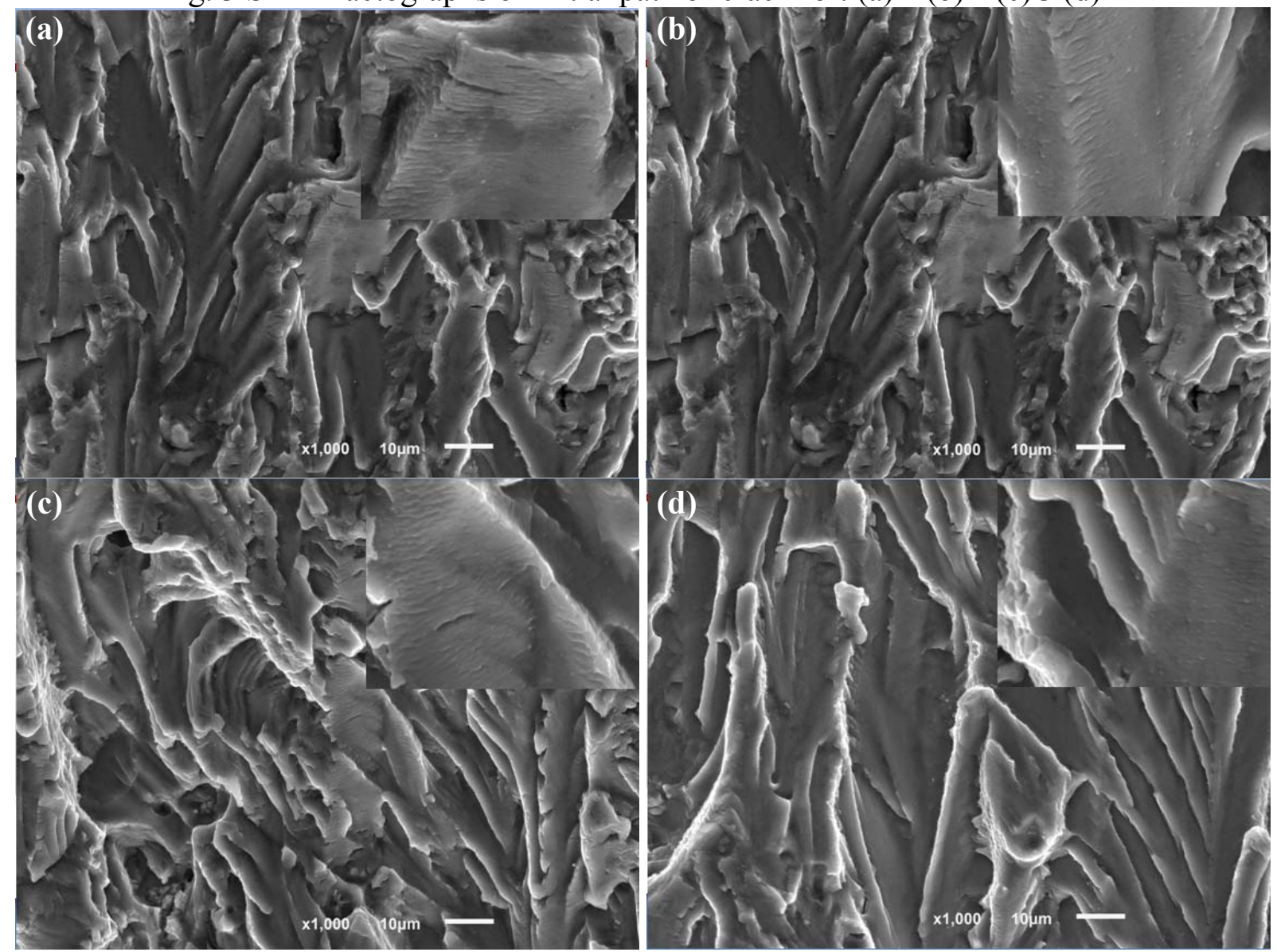

Fig. 4 SEM fractographs of steady propagation region for: (a)A (b)B (c)C (d)D 

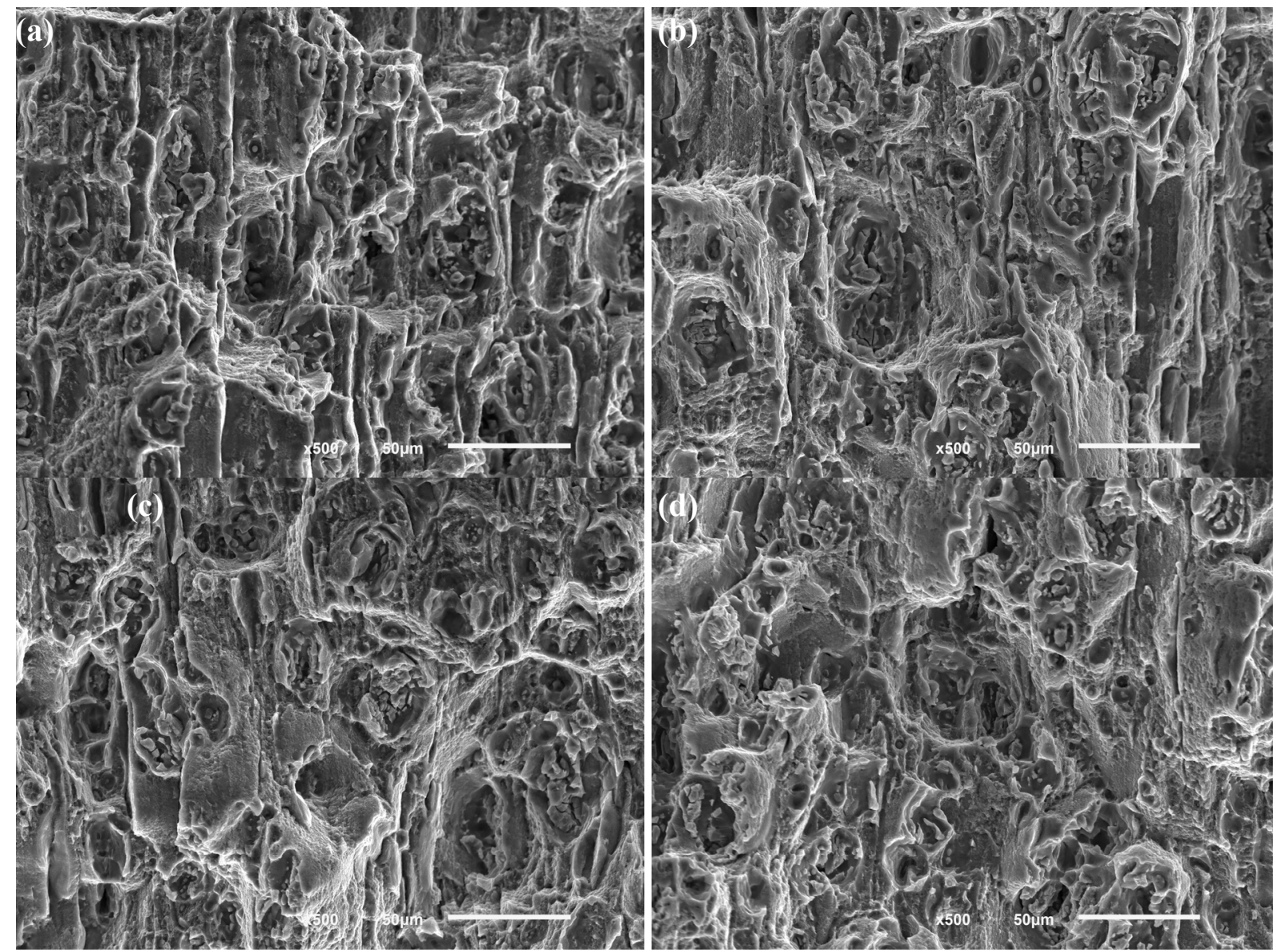

Fig. 5 SEM fractographs of fatigue final rupture region for: (a)A (b)B (c)C (d)D

\subsection{XRD analysis}

In order to study the mechanism of cryogenic treatment, X-ray diffraction pattern before and after cryogenic treatment of 7075 aluminum alloy was applied. The XRD patterns (shown in Fig. 6) depicted the characteristic peaks of 7075 aluminum alloy after different cryogenic treatments, which corresponded to (111), (200), (220) and (311) reflection plane of $\alpha(\mathrm{Al})$. It can be seen, after different cryogenic treatment, the intensity of the XRD diffraction peak value changed. Table 3 reflected the change of XRD diffraction peak intensity of 7075 aluminum alloy in some major diffraction crystal. The diffraction peak intensity of (200) had obvious enhancement with the decrease of cryogenic temperature, but to a certain degree and then fell, which reached the maximum value after the cryogenic treatment of $-120{ }^{\circ} \mathrm{C}$. The trendency of XRD diffraction peak intensity of (200) was in consistence with that of fatigue crack propagation behavior of 7075 aluminum alloy after cryogenic treatment. 


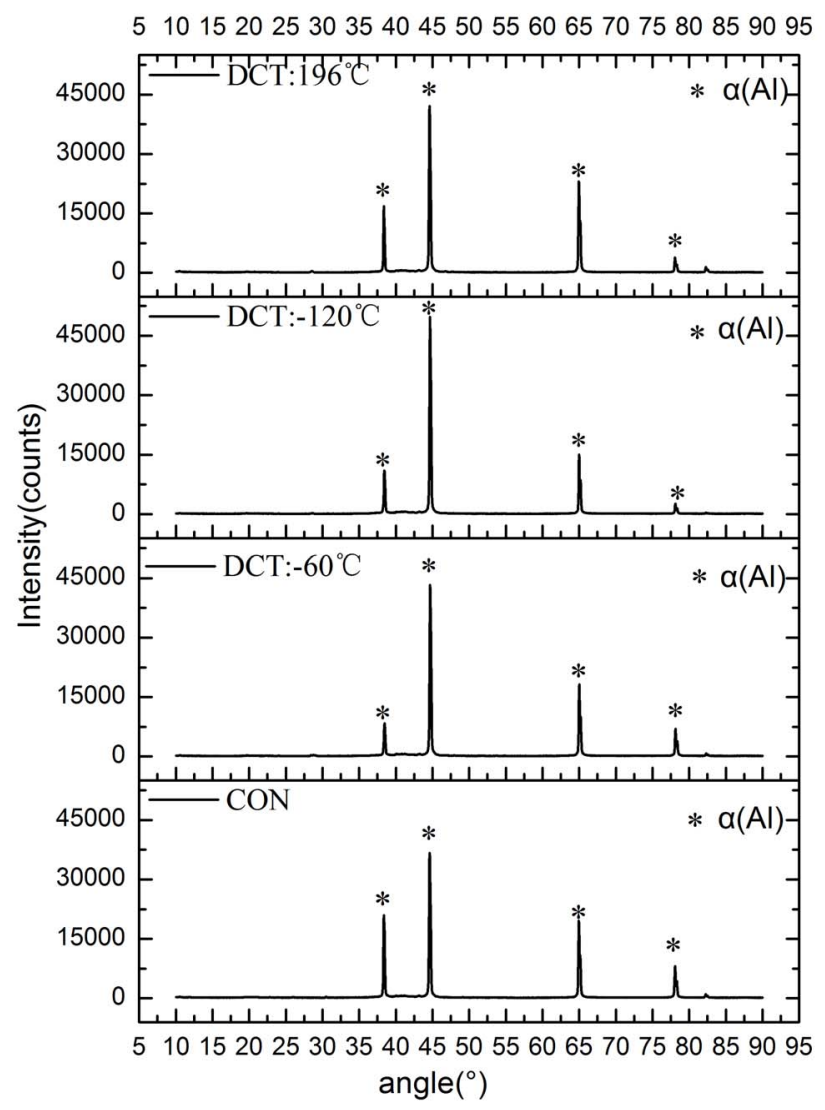

Fig. 6 XRD patterns of 7075 aluminum alloy after different cryogenic treatment

The change of XRD diffraction peak intensity suggested the cryogenic treatment can induce the (200) peak preferred orientation. In the process of cooling, a lot of dislocations and subgrains were generated within the material due to the volume shrinkage effect [10]. In following process of heating, recovery recrystallization occurred with grains of aluminum alloy rotating on the preferred orientation, which leaded the formation of recrystallization texture. When the grain orientation was helpful to inhibit dislocation motion, the fatigue crack propagation property of 7075 aluminum alloy was improved.

Table 3 Change of the diffraction peak intensity

\begin{tabular}{ccccc}
\hline \multirow{2}{*}{ Number } & \multicolumn{4}{c}{ Absolute intensity (Relative intensity/\%) } \\
\cline { 2 - 5 } & $(111)$ & $(200)$ & $(220)$ & $(311)$ \\
\hline A & $20943(57.37)$ & $36505(100)$ & $19601(53.69)$ & $8086(22.2)$ \\
B & $8249(19.04)$ & $43319(100)$ & $17542(40.49)$ & $7038(16.2)$ \\
C & $11046(22.68)$ & $48707(100)$ & $15020(30.84)$ & $2699(5.54)$ \\
D & $16895(40.14)$ & $42093(100)$ & $23061(54.79)$ & $3741(8.89)$ \\
\hline
\end{tabular}

\section{Conclusion}

1. The cryogenic treatment as an additional heat treatment process has been showed to improve the fatigue performance of 7075 aluminum alloy. 7075 aluminum alloy obtained the best fatigue performance after the cryogenic treatment of $-120{ }^{\circ} \mathrm{C}$.

2. The XRD result showed the cryogenic treatment, especially at the cryogenic temperature of $-120{ }^{\circ} \mathrm{C}$, caused the XRD diffraction peak intensity of (200) obvious enhanced, which suggested the cryogenic treatment can induce the (200) peak preferred orientation.

3. The proposed mechanism for the improvement in fatigue crack propagation property is that the (200) peak preferred orientation can be induced through the cryogenic treatment. 


\section{References}

[1] D. K. Xu, N. Birbilis, D. Lashansky, P. A. Rometsch, B. C. Muddle: Corros. Sci. Vol. 53(2011), p. $217-225$

[2] El-Amoush, A. Saleh: Mater. Chem. Phys. Vol. 12(2011), p. 607-613

[3] A. Bensely, A. Prabhakaran, D. Mohan Lal, G. Nagarajan: CRYOGENICS Vol. 45(2005), p. 747-754

[4] S. Zhirafar, A. Rezaeian, M. Pugh: J. Mater. Process. Technol. Vol. 186(2007), p. 298-303

[5] N. Naya, S.V.S. Narayana Murty, A. K. Jha, B. Pant, S.C. Sharma, K.M. George, G.V.S. Sastry: Mater. Des. Vol. 58(2014), p. 445-450

[6]J. Wang, R.D. Fu, Y.J. Li, J.F. Zhang: Mater. Sci. Eng., A. Vol. 609(2014), p. 147-153

[7] X.Q. Jiang, N. Li, H. He, X.J. Zhang, C.C. Li, H. Yang: Mater. Sci. Forum Vol. 546-549(2007), p. 845-848

[8] A. Akhbarizadeh, A. Shafyei, M.A. Golozar: Mater. Des. Vol. 30(2009), p. 3259-3264

[9] C.M. Li, N.P. Cheng, Z.Q. Chen, N. Guo, S.M. Zeng: Int. J. Miner. Metall. Mater. Vol. 22(2015), p. $68-77$

[10]D. Chen, W.X. Li: Chin. J. Nonferrous Met. Vol. 10(2000), p. 891-895

[11]L.L. Wei, Q.L. Pan, H.F.Huang, L. Feng, Y.L. Wang: Int. J. Fatigue. Vol. 66(2014), p.55-64 